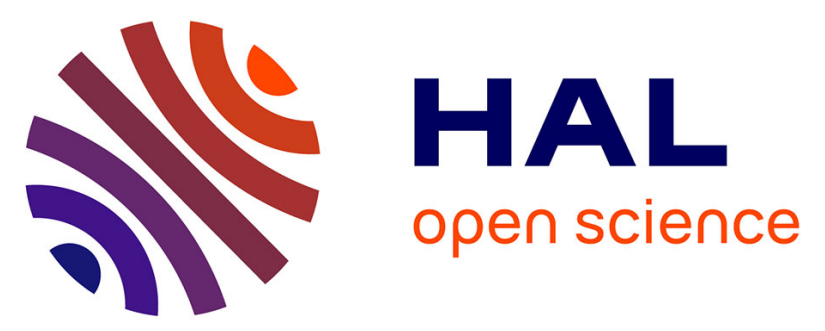

\title{
Structural and Magnetic Implications of Transition Metal Migration within Octahedral Core-Shell Nanocrystals
}

\author{
Beatriz Rivas-Murias, Martín Testa-Anta, Pau Torruella, Sònia Estradé, \\ Francesca Peiró, Benito Rodríguez-González, Miguel Comesaña-Hermo, \\ Verónica Salgueiriño
}

\section{To cite this version:}

Beatriz Rivas-Murias, Martín Testa-Anta, Pau Torruella, Sònia Estradé, Francesca Peiró, et al.. Structural and Magnetic Implications of Transition Metal Migration within Octahedral Core-Shell Nanocrystals. Chemistry of Materials, 2020, 32 (24), pp.10435-10446. 10.1021/acs.chemmater.0c03017 . hal-03054557

\section{HAL Id: hal-03054557 https://hal.science/hal-03054557}

Submitted on 4 Jan 2021

HAL is a multi-disciplinary open access archive for the deposit and dissemination of scientific research documents, whether they are published or not. The documents may come from teaching and research institutions in France or abroad, or from public or private research centers.
L'archive ouverte pluridisciplinaire HAL, est destinée au dépôt et à la diffusion de documents scientifiques de niveau recherche, publiés ou non, émanant des établissements d'enseignement et de recherche français ou étrangers, des laboratoires publics ou privés. 


\section{Structural and Magnetic Implications of Transition}

\section{Metal Migration within Octahedral Core-Shell}

\section{Nanocrystals}

Beatriz Rivas-Murias, ${ }^{1,2} *$ Martín Testa-Anta, ${ }^{1,3}$ Pau Torruella, ${ }^{4,5}$ Sònia Estradé, ${ }^{4,5}$ Francesca Peiró, ${ }^{4,5}$ Benito Rodríguez-González, ${ }^{2}$ Miguel Comesaña-Hermo, ${ }^{6}$ Verónica Salgueiriñoo ${ }^{1,3 *}$ ${ }^{1}$ Departamento de Física Aplicada, Universidade de Vigo, 36310, Vigo (Spain)

${ }^{2}$ CACTI, Universidade de Vigo, 36310, Vigo (Spain)

${ }^{3}$ CINBIO, Universidade de Vigo, 36310, Vigo (Spain)

${ }^{4}$ Laboratory of Electron Nanoscopies, Departament d'Enginyeria Electrònica i Biomèdica, Universitat de Barcelona, 08028, Barcelona (Spain)

${ }^{5}$ Institute of Nanoscience and Nanotechnology, Universitat de Barcelona, 08028, Barcelona (Spain)

${ }^{6}$ Université de Paris, ITODYS, CNRS, F-75006 Paris (France) 


\begin{abstract}
Octahedron-shaped cobalt oxide nanocrystals undergo a structural evolution once coated with thin shells of manganese or cobalt ferrite, by means of an asymmetric solid-solid diffusion occurring at the interface established between the oxides. The resultant mixed ferrites in the final nanostructures stem from the phase progression associated to a non-equilibrium kinetic product that evolves to reach the thermodynamic equilibrium. In this process, the initially strained crystalline lattice closer to the interface influences the progressive redistribution of $\mathrm{Co}^{2+}$ cations diffusing out of the initial cobalt oxide core, dictating the final magnetic properties. When starting with a non-stoichiometric manganese ferrite shell, the preferential occupation of tetrahedral sites by $\mathrm{Mn}^{2+}$ cations forces the $\mathrm{Co}^{2+}$ to occupy octahedral sites, offering a $\mathrm{Mn}$ - and Co-doped magnetite shell onto the $\mathrm{CoO}$ core. However, when starting with a cobalt ferrite shell, an extra doping of $\mathrm{Co}^{2+}$ cations in the strained layers close to the interface forces this ferrite to transition from the inverse to the normal spinel structure, leading to core-shell nanocrystals of $\mathrm{CoO}$ and Co-rich cobalt ferrite with an enhanced magnetic moment.
\end{abstract}




\section{Introduction}

The preparation of magnetic nanostructures with ever increasing compositional complexities and exotic morphologies has led to functional materials that are currently implemented in different fields. ${ }^{1}$ More specifically, those of transition metal oxides, with a crystalline ionic configuration of metal cations with unfilled $d$-electron orbitals, have become key in fields related to energy and magnetism. This stems mainly from the ease of removing and adding electrons to these orbitals that permits different oxidation states, and that is responsible for the vast number of studies in which these materials are implemented in processes related to catalysis, ${ }^{2,3}$ chemical looping for batteries, ${ }^{4-6}$ and spintronics. ${ }^{7,8}$

The reduced dimensionality of magnetic nanostructures can result in significant changes in the magnetic behavior, ${ }^{9,10}$ not only owing to the highly correlated $d$ electrons mentioned, ${ }^{11}$ but also due to confinement effects, ${ }^{12-14}$ which can be taken into consideration at interfaces created when combining these oxides with low dimensionalities. Along these lines, an interface embodies an interesting source of relevant structural effects (auxetic to non-auxetic crossover) ${ }^{15}$ or magnetic interactions (spin canting, exchange bias or charge transfer) ${ }^{16}$ that can lead to synergies and eventually to a completely new set of electronic/magnetic features. ${ }^{17}$ Moreover, interfacial phenomena can offer a way to reach phases that are thermodynamically stable but cannot be synthesized experimentally, by means of a solid state chemistry path through multiple non-equilibrium intermediates. ${ }^{18}$ Indeed, the use of interfaces as the starting point in preparative solid-state chemistry takes into account an evolution of the metastable compounds located in their surroundings towards a situation of local minima in the thermodynamic landscape. Consequently, an original mechanistic pathway can be explored for the synthesis of new solids and a deeper understanding of their ultimate functions, ${ }^{19,20-}$ ${ }^{22}$ providing therefore an unprecedented degree of control when referred to the magnetic properties of transition metal oxides at the nanoscale. 
Particularly, the magnetic nanostructures of $3 d$-transition metal oxides, porous and/or hollow, are gaining relevance due to their low densities, large surface areas and reduced length for both mass and charge transport properties. Such characteristics are currently implemented to maximize performances in fields related to Li-ion batteries, theranostics or catalysis. ${ }^{20-23}$ In opposition to the use of sacrificial templates for the formation of hollow structures, ${ }^{24}$ there are different diffusiondriven processes, for example taking advantage of the Kirkendall effect ${ }^{25-28}$ or galvanic transformations $s^{20,29}$ that have proven to be particularly useful. In fact, solid-solid diffusion processes imply a privileged strategy because the atoms and vacancies that form these crystalline solids are not static but rather mobile entities that can experience dynamic processes. ${ }^{30}$ Such phenomena endow the hybrid systems in consideration with rich chemical characteristics that have an important impact in the magnetic properties derived. Moreover, they permit the formation of equilibrium stoichiometries, holding the system under appropriate thermodynamic conditions (temperature and pressure) for a sufficiently long time. ${ }^{18}$

In the present work, we detail the structural and magnetic characterization of transition metal oxide nanostructures that result from the coating of cobalt oxide octahedron-shaped nanocrystals with a thin shell of manganese or cobalt ferrite by means of a thermal decomposition process. This study reveals a structural evolution stemming from a solid-solid diffusion process starting at the core-shell interface, which directs the magnetic properties of the final hybrid material. The mechanism proposed is supported by a comprehensive and multi-instrumental study considering Raman spectroscopy and advanced electron microscopy techniques, jointly with magnetic measurements, which permits an indepth characterization of the octahedron-shaped final nanostructures and allows us to correlate the changes of the total magnetic moment with the reconfiguration of the magnetic cations in the spinel structure. To explain the mixing and hollowing process observed, we have taken into account the cation vacancies and interstitials as the most important point defects, while considering that oxygen diffusion is always a much slower process to drive and influence the solid-solid diffusion itself. ${ }^{31}$ 


\section{Experimental}

Synthesis of octahedron-shaped cobalt oxide nanoparticles. Cobalt(II) acetate tetrahydrate (1 $\mathrm{mmol})$, trioctylphosphine oxide (TOPO, $0.2 \mathrm{mmol})$, oleic acid $(8 \mathrm{mmol})$ and oleylamine $(14.3 \mathrm{mmol})$ were added into a three-necked round-bottomed flask containing $25 \mathrm{~mL}$ of trioctylamine (TOA), in open air conditions. The temperature was increased up to $140{ }^{\circ} \mathrm{C}\left(6^{\circ} \mathrm{C} / \mathrm{min}\right.$ ramp rate $)$ and then kept at this temperature with magnetic stirring for $45 \mathrm{~min}$. After this dwell period, the solution was again heated to reflux up to $300{ }^{\circ} \mathrm{C}\left(3{ }^{\circ} \mathrm{C} / \mathrm{min}\right.$ ramp rate $)$. Upon reaching the reflux, the solution was kept at this temperature for $5 \mathrm{~h}$ and subsequently cooled down to room temperature. Finally, the nanoparticles were washed by centrifugation and redispersed in ethanol.

\section{Synthesis of $\mathrm{CoO} @ \mathrm{MnFe}_{2} \mathrm{O}_{4}$ (CoO@MFO) and $\mathrm{CoO} @ \mathrm{CoFe}_{2} \mathrm{O}_{4}$ (CoO@CFO) core-shell} octahedra. For this synthesis, the previously synthesized octahedron-shaped cobalt oxide nanoparticles were used as seeds for the thermal decomposition of iron (II) and manganese (II) or iron (II) and cobalt (II) acetate precursors by means of a hot-injection procedure. Thus, Thus, $20 \mathrm{mg}$ of the pre-synthesized cobalt oxide nanoparticles $(0.267 \mathrm{mmol})$ of the pre-synthesized cobalt oxide nanoparticles (as solid material), $1.6 \mathrm{mmol}$ of oleic acid and $25 \mathrm{~mL}$ of TOA were placed in a threenecked round-bottomed flask and heated up to $210{ }^{\circ} \mathrm{C}$ under stirring. Once this temperature was reached, a $500 \mu \mathrm{L}$ solution including $19.16 \mu \mathrm{mol}$ of iron (II) acetate and $9.58 \mu \mathrm{mol}$ of manganese (II) or cobalt(II) acetate dissolved in ethanol was injected dropwise, trying to avoid an important decrease in temperature. After that, the solution was heated up to reflux $\left(\sim 300{ }^{\circ} \mathrm{C}, 3{ }^{\circ} \mathrm{C} / \mathrm{min}\right.$ ramp rate $)$ and kept at this temperature for $3 \mathrm{~h}$. Upon heating, the solution changed color from brown to black. Once cooled to room temperature, ethanol $(\sim 25 \mathrm{~mL})$ was added into both solutions to precipitate nanoparticles, helped by centrifugation. The nanoparticles were thus separated from the supernatant containing the solvent, ligands and by-products. This procedure was repeated at least three times.

Characterization. Samples for transmission electron microscopy (TEM) analysis were prepared by drop casting a diluted suspension of the nanoparticles onto an ultrathin carbon coated copper grid. 
TEM measurements were performed on a JEOL JEM1010 instrument operating at an acceleration voltage of $100 \mathrm{kV}$. High resolution transmission electron microscopy (HRTEM), high-angle annular dark-field scanning transmission electron microscopy (HAADF STEM) and energy dispersive X-ray elemental analyses (EDS) were carried out on a field emission JEOL JEM2010F TEM working at 200 kV. STEM-HAADF imaging, electron energy loss spectroscopy (EELS), HAADF-tomography and EELS-tomography were performed in a JEOL ARM200F equipped with a Quantum GIF spectrometer. Inspect3D software was used for the tomography reconstruction. X-ray diffraction patterns were collected using a Panalytical X'Pert Pro diffractometer $(\mathrm{Cu} \mathrm{K} \alpha$ radiation and BraggBrentano $\theta-2 \theta$ geometry) in the $10-80^{\circ} 2 \theta$ range. Raman spectra were collected with a Renishaw in Via Reflex Confocal Raman Microscope. These experiments were registered in backscattering geometry at room temperature using a $785 \mathrm{~nm}$ laser excitation wavelength. The laser beam was focused on the sample by a 20x objective, with a numerical aperture (NA) value of 0.40 . The laser powers used were below $1 \mathrm{~mW}$ to avoid overheating on the samples. Magnetic measurements were performed using the VSM option in a Physical Property Measurement System (PPMS) from Quantum Design. Hysteresis loops were measured at 10 and $325 \mathrm{~K}$ up to an external field of $7 \mathrm{~T}$. FC hysteresis loops were performed at $10 \mathrm{~K}$, applying a magnetic field of $5 \mathrm{~T}$ in the cooling process from $340 \mathrm{~K}$. The magnetization dependence with temperature in zero-field-cooled (ZFC) and field-cooled (FC) conditions was performed at $10 \mathrm{mT}$ in the $5-330 \mathrm{~K}$ range. All magnetic measurements were performed using dried powdered samples. 
Results and Discussion

Figure 1 includes low and high magnification TEM images with general overviews of the three samples considered in this study, starting with octahedron-shaped cobalt oxide nanoparticles (hereafter labelled as $\mathrm{CoO}$, figures $1 \mathrm{a}$ and $1 \mathrm{~b}$ ), subsequently coated with a thin layer of manganese ferrite (hereafter labelled as $\mathrm{CoO} @ \mathrm{MFO}$, figures 1d and 1e) or cobalt ferrite (hereafter labelled as CoO@CFO, figures $1 \mathrm{~g}$ and $1 \mathrm{~h}$ ), obtained in independent experiments. In the three cases we can appreciate the octahedral shape, perfectly defined in the initial $\mathrm{CoO}$ nanocrystals with flat surface facets that subsequently evolve to more irregular morphologies for the $\mathrm{CoO} @ \mathrm{MFO}$ and $\mathrm{CoO} @ \mathrm{CFO}$ samples, respectively. Likewise, the nanocrystals display cracks in their interior which become gradually more relevant for the $\mathrm{CoO} @ \mathrm{MFO}$ and $\mathrm{CoO} @ \mathrm{CFO}$ systems, respectively. Additionally, the histograms plotting the particle size distribution (i.e., the edge length distribution) and their fit to a log-normal function for the three samples are shown, with average edge length values $l=50.4 * / 1.6$ $\mathrm{nm}$ (for the $\mathrm{CoO}$ sample, figure 1c), $l=41.9 * / 1.5 \mathrm{~nm}$ (for the CoO@MFO sample, figure 1f) and $l$ $=37.3 * / 1.4 \mathrm{~nm}$ (for the CoO@CFO sample, figure 1i), attending to the fact that it is more accurate to reflect the size distribution in terms of a log-normal function, with the geometric mean multiplied or divided by the square of the standard deviation $\left(l=\overline{\mathrm{x}}^{*} * /\left(\mathrm{s}^{*}\right)^{2} \mathrm{~nm}\right.$, containing $95.5 \%$ of the nanoparticles). ${ }^{32}$ Surprisingly, coating the initial $\mathrm{CoO}$ octahedra either with manganese or cobalt ferrite leads to a shrinkage of the average size of the final nanocrystals. 

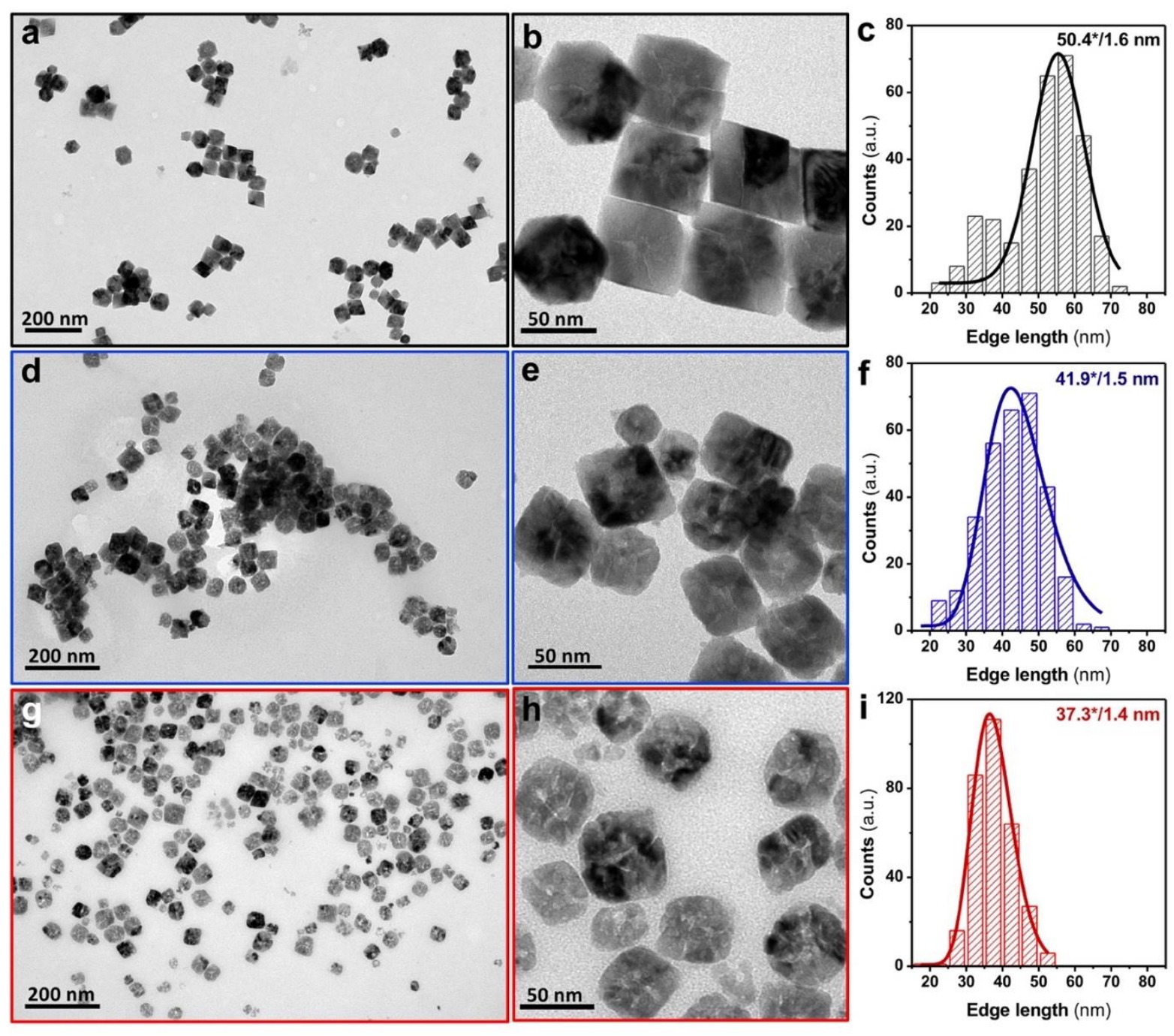

Figure 1. Lower and higher magnification TEM images with general overviews and corresponding histograms plotting the particle size distribution (considering the octahedron edge length and fitted to a log-normal function) of the $\mathrm{CoO}(\mathrm{a}, \mathrm{b}$ and c), $\mathrm{CoO} @ \mathrm{MFO}(\mathrm{d}, \mathrm{e}$ and $\mathrm{f})$ and $\mathrm{CoO} @ \mathrm{CFO}$ (g, h and i) samples.

To understand the shrinkage of the nanocrystals once coated, we have studied the internal morphology of the $\mathrm{CoO} @ \mathrm{MFO}$ and $\mathrm{CoO} @ \mathrm{CFO}$ samples. Figures 2a and 2b include HAADF images (in STEM mode) of these nanostructures, revealing the presence of defects or voids as regions of lower density, despite the fact of maintaining in most of the cases the octahedral shape and the faceted outer surface. These voids, present in the $\mathrm{CoO}$ initial sample, become larger in the $\mathrm{CoO} @ \mathrm{MFO}$ and CoO@CFO samples, implying therefore additional solid-state diffusion processes and 
intermixing. ${ }^{19,29,33,34}$ Hence, first, in order to obtain an in-depth understanding of the structural features of these nanostructures, Raman spectroscopy was employed. This technique has proven to be particularly useful in those cases in which chemical segregation and/or cation doping lead to the formation of complex interfaces in oxides. ${ }^{35}$ According to the literature, while $\mathrm{CoO}$, which is a weak Raman scatterer, shows a broad band (one-phonon LO mode) at $\sim 530 \mathrm{~cm}^{-1},{ }^{36-38}$ the general $\mathrm{AB}_{2} \mathrm{O}_{4}$ spinel lattice exhibits five Raman-active modes (one $A_{1 g}$, one $E_{g}$, and three $T_{2 g}$ modes). ${ }^{39,40}$ The highest-frequency $\mathrm{A}_{1 \mathrm{~g}}$ mode of the spinel structure, attributed to the symmetric stretching of oxygen atoms ("breathing motion") in the tetrahedral $\mathrm{AO}_{4}$ void ${ }^{41-43}$ along the cubic $\langle 111\rangle$ direction, ${ }^{44}$ is typically the most intense and is usually located at approximately $600-750 \mathrm{~cm}^{-1}$. The remaining lowfrequency modes also reflect a rather strong influence of the tetrahedral sites, although these units are not completely isolated but surrounded by three octahedral units. This last fact renders Raman spectroscopy a valuable tool to ascertain different cationic rearrangements within the spinel structure. Figure 2c displays the Raman spectra registered from the CoO@MFO (blue) and the $\mathrm{CoO} @ \mathrm{CFO}$ (red) samples, besides the one from the $\mathrm{CoO}$ sample as reference (in black), which shows its characteristic band at $533 \mathrm{~cm}^{-1}$ (shadowed in grey). The spectrum of the $\mathrm{CoO}$ sample displays an additional band at $690 \mathrm{~cm}^{-1}$, which can be associated to the native oxidation of $\mathrm{CoO}$ to $\mathrm{Co}_{3} \mathrm{O}_{4}$ at the surface of the octahedra (the main $\mathrm{T}_{2 \mathrm{~g}}, \mathrm{E}_{\mathrm{g}}$ and $\mathrm{A}_{1 \mathrm{~g}}$ bands of the spinel $\mathrm{Co}_{3} \mathrm{O}_{4}$ appear shadowed in yellow in the graph). ${ }^{36,45,46}$

Considering first the $\mathrm{CoO} @ \mathrm{MFO}$ nanocrystals, besides the distinctive feature from $\mathrm{CoO}$, three additional bands centered at 192, 484 and $691 \mathrm{~cm}^{-1}$ (shadowed in yellow) can be observed, indicating the presence of $\mathrm{Co}_{3} \mathrm{O}_{4}$ within the nanocrystals. The presence of a manganese-based ferrite can be also evidenced by the two small shoulders located at 630 and $658 \mathrm{~cm}^{-1}$ (indicated by blue dotted lines in figure 2c). Whereas the $\mathrm{A}_{1 \mathrm{~g}}$ mode from the $\mathrm{MnFe}_{2} \mathrm{O}_{4}$ phase is usually located in the $600-625 \mathrm{~cm}^{-1}$ region, the characteristic $A_{1 \mathrm{~g}}$ mode from magnetite is known to appear at $\sim 660-670 \mathrm{~cm}^{-1}$. The observation of the mode at $630 \mathrm{~cm}^{-1}$ proves therefore the insertion of $\mathrm{Mn}^{2+}$ cations into the tetrahedral 
sites of a spinel ferrite structure. Likewise, the fact that we have registered a second mode at $658 \mathrm{~cm}^{-1}$ indicates the presence of manganese-doped magnetite, though not homogeneous throughout the sample, as confirmed by scanning different spots (see figure S1 in the Supporting Information, SI).
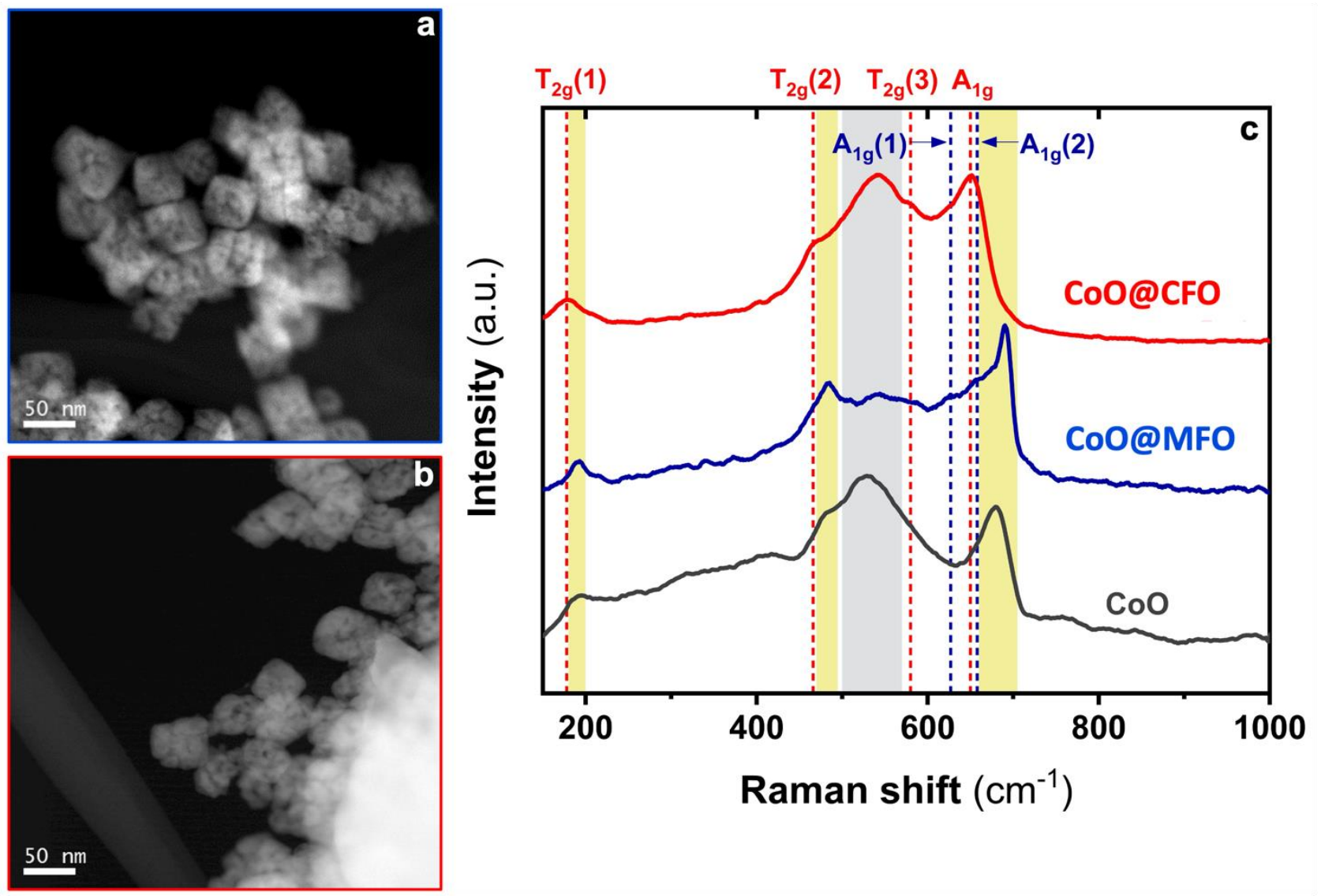

Figure 2. HAADF-STEM images of the nanocrystals from $\mathrm{CoO} @ \mathrm{MFO}$ (framed in blue) and CoO@CFO (framed in red) samples ( $\mathrm{a}$ and b). Stokes-shifted Raman spectra of CoO@MFO (in blue) and CoO@CFO (in red) samples obtained using a $785 \mathrm{~nm}$ excitation wavelength. The Raman spectrum of $\mathrm{CoO}$ (in black) is also included as reference. Grey and yellow regions correspond to the position of $\mathrm{CoO}$ and $\mathrm{Co}_{3} \mathrm{O}_{4}$ Ramans bands (c).

Regarding the $\mathrm{CoO} @ \mathrm{CFO}$ nanocrystals, the presence of $\mathrm{CoO}$ can be analogously evidenced from the main feature at $540 \mathrm{~cm}^{-1}$, whereas the bands located at 470 and $650 \mathrm{~cm}^{-1}$ can be presumably ascribed to the $\mathrm{T}_{2 \mathrm{~g}}(2)$ and $\mathrm{A}_{1 \mathrm{~g}}$ phonon modes of the $\mathrm{CoFe}_{2} \mathrm{O}_{4}$ spinel structure, respectively (indicated by red dotted lines). Due to the presence of two different cations at the octahedral sites of its inverse spinel structure, $\mathrm{CoFe}_{2} \mathrm{O}_{4}$ typically displays a splitting of the $\mathrm{A}_{1 \mathrm{~g}}$ mode, leading to one intense mode 
accompanied by a small shoulder at lower frequencies. Interestingly, the more intense $\mathrm{A}_{1 \mathrm{~g}}$ mode $\left(\mathrm{A}_{1 \mathrm{~g}}\right.$ (2)) appears shifted if compared to the values reported in the literature for the stoichiometric inverse cobalt ferrite. Given the fact that this vibrational mode is highly sensitive to cation redistribution, ${ }^{47,48}$ this redshift observed points to a scenario in which a cationic rearrangement has taken place, leading to a cobalt-rich ferrite shell. Even though the presence of tensile strain within the attained nanostructures may also contribute to the $\mathrm{A}_{1 \mathrm{~g}}$ redshift, the fact that the remaining modes remain unshifted evidences an intermixing process as the main driving force. This experimental Raman analysis, jointly with the observations of the HAADF-STEM images, suggest simultaneous and progressive inwards and outwards cation diffusion processes that cause a shrink of the octahedra average size while rendering the nanostructures porous/hollow. Figure S2 (in the SI) includes the powder diffractograms of $\mathrm{CoO} @ \mathrm{MFO}$ and $\mathrm{CoO} @ \mathrm{CFO}$, showing that the presence of the rock-salt $\mathrm{CoO}$ crystalline structure screens the spinel structure registered by Raman spectroscopy in both samples. Diffracted peaks associated to the spinel structure with very low intensities (indicated by black arrows) and a peak associated to metallic iron (bcc structure) were also registered. Since starting with nanocrystals with voids and cracks inside, this can also imply that each nanostructure is polycrystalline, as suggested from the XRD patterns of the samples. Indeed, when applying the Scherrer equation to the (111) diffracted peak, an average $\sim 23 \mathrm{~nm}$ crystallite size is obtained. 


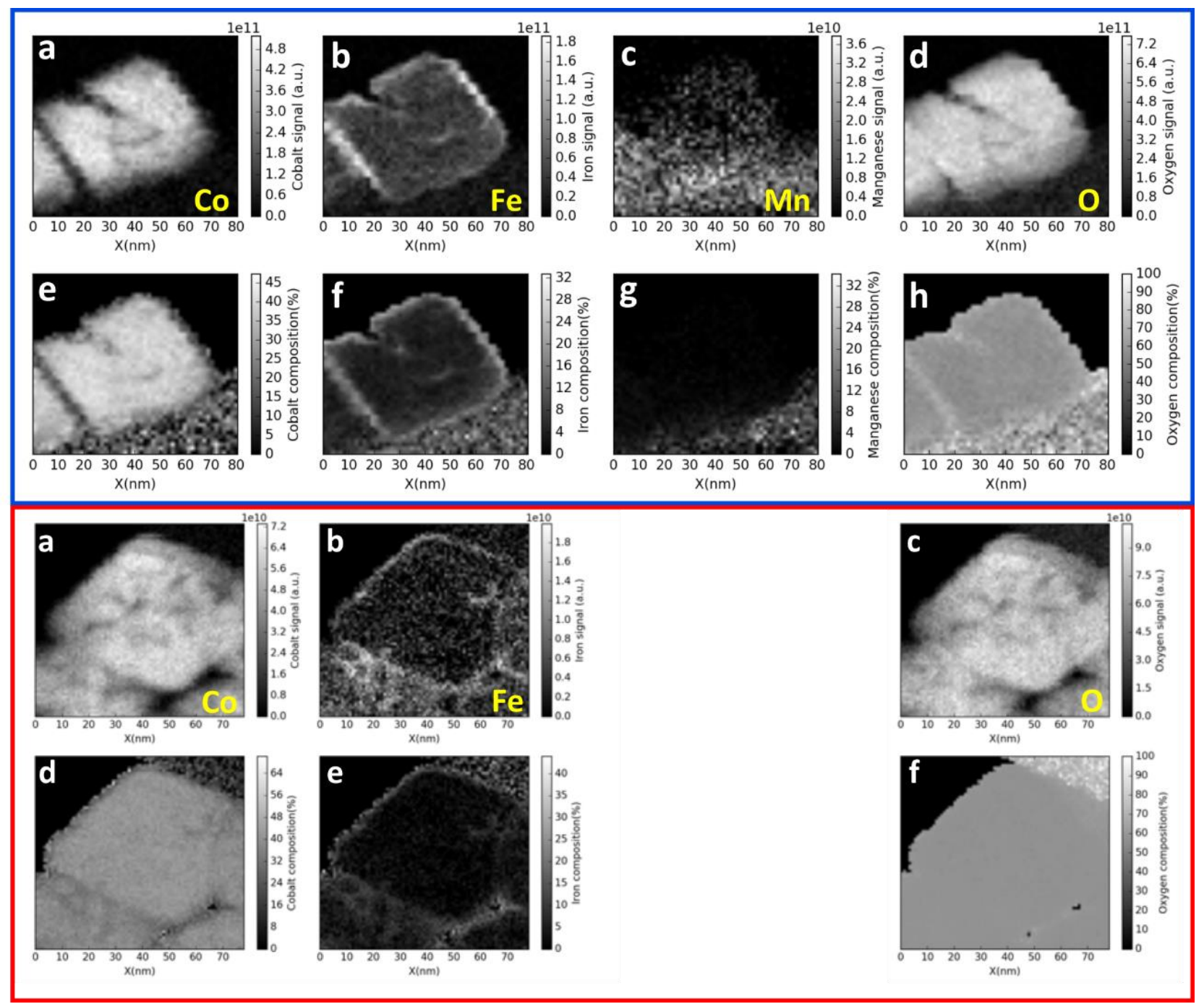

Figure 3. EELS analysis from a nanocrystal of CoO@MFO (top blue panel) or CoO@ CFO (bottom red panel). EELS signal and relative composition for: cobalt (a and e), iron (b and f), manganese (c and $\mathrm{g}$ ) and oxygen $(\mathrm{d}$ and $\mathrm{h}$ ) in the blue panel. The rippling of the outer surface is an artefact from the spatial drift correction used during the acquisition. EELS signal and relative composition for: cobalt (a and d), iron (b and e) and oxygen (c and f) in the red panel.

Having the intermixing process in mind, a more detailed HRTEM analysis combined with EELS mapping and tomography reconstruction was performed for the $\mathrm{CoO} @ \mathrm{MFO}$ and $\mathrm{CoO} @ \mathrm{CFO}$ nanocrystals. Figure 3 shows the EELS analysis of a representative nanocrystal from the CoO@MFO sample (top blue panel) and from the $\mathrm{CoO} @ \mathrm{CFO}$ sample (bottom red panel). For each image, the Co (780 eV), Fe $(710 \mathrm{eV}), \mathrm{Mn}(640 \mathrm{eV})$ and $\mathrm{O}(530 \mathrm{eV})$ peaks have been mapped. In both cases, the Fe 
elemental maps clearly reveal the presence of an iron rich layer of $\sim 3 \mathrm{~nm}$ on the surface of the nanocrystal (figures $3 \mathrm{~b}$ and $3 \mathrm{f}$ of the blue panel for the CoO@MFO sample and figures $3 \mathrm{~b}$ and $3 \mathrm{e}$ of the red panel for the $\mathrm{CoO} @ \mathrm{CFO}$ sample), which we associate to the spinel ferrite shells formed and registered by Raman spectroscopy. For the $\mathrm{CoO} @ \mathrm{MFO}$ sample, the manganese present could only be detected after the use of a sophisticated statistical analysis (PCA, Principal Components Analysis), since its relative composition is below 5\%. The composition analysis for the outer shell of this sample indicates however the formation of a material richer in cobalt, with an approximate average $\mathrm{Mn}_{0.4} \mathrm{Co}_{1.8} \mathrm{Fe}_{0.8} \mathrm{O}_{4}$ spinel stoichiometry. Note that although the manganese signal image looks relatively clear, the intensity is an order of magnitude lower than that of iron or cobalt. For the $\mathrm{CoO} @ \mathrm{CFO}$ sample, the EELS analysis of the outer shell reveals an average $\mathrm{Co}{ }_{1.9} \mathrm{Fe}_{1.1} \mathrm{O}_{4}$ composition, assuming again the spinel crystalline structure. These stoichiometric ratios for the spinel shell in both samples are averaged over the whole shells, but the fact of observing clear iron-rich outer areas (see figures $3 \mathrm{~b}$ and $3 \mathrm{f}$ in the blue panel and figures $3 \mathrm{~b}$ and $3 \mathrm{e}$ in the red panel) points more to a negative gradient of cobalt as moving in the outward direction.

Furthermore, a 3D tomographic reconstruction of the nanocrystals obtained from the EELS signal collected was carried out, in order to obtain a more graphical picture of the internal morphology. Figures $4 \mathrm{a}$ and $4 \mathrm{~b}$ depict the representative HAADF tomography images of two different nanocrystals from the CoO@MFO sample. The reconstruction using the cobalt signal is shown in figures 4c and $4 \mathrm{~d}$, on which we can appreciate the edges of the octahedron shape highlighted with black dotted lines (figure 4c) or an internal channel up to the surface of the nanocrystal (figure 4d). Since the iron and manganese signals were too low to produce a reliable $3 \mathrm{D}$ reconstruction, we have taken advantage of a 3D reconstruction based on the oxygen signal (figures $4 \mathrm{e}$ and $4 \mathrm{f}$ ). These $3 \mathrm{D}$ reconstructions depict the nanocrystals with a larger volume than in figures $4 \mathrm{c}$ and $4 \mathrm{~d}$, which means that there is a uniform outer layer of an oxide at the surface of the nanocrystal, corroborated also with the previous EELS analyses shown in figure 3 (blue panel). When plotting both reconstructions together (i.e. considering 
the cobalt and oxygen signals), as shown in figures $4 \mathrm{~g}$ and $4 \mathrm{~h}$, a clear image of the core-shell structure emerges. Analogously, figure 5 includes the 3D tomographic reconstruction of a nanocrystal from the $\mathrm{CoO} @ \mathrm{CFO}$ sample, which confirms a more advanced deformation of the original octahedral shape. Nevertheless, eight triangular facets can still be observed (highlighted with black dotted lines, figure $5 b$ ) together with the presence of voids and channels within the structure. Indeed, one of the surface facets shows an aperture that is attributed to the presence of one of the channels towards the surface (seen in figures $5 \mathrm{a}, 5 \mathrm{~d}, 5 \mathrm{e}, 5 \mathrm{~g}$ and $5 \mathrm{j}$ ). The bulk of the particle mainly consists of cobalt-based oxide, with the iron seemingly distributed throughout the structure following a complex grid of channels and small voids, supporting the idea that solid-solid diffusion processes took place. Such finding also highlights the presence of a $\sim 3 \mathrm{~nm}$ outer iron-based layer, as clearly reflected in this 3D reconstruction. Moreover, the presence of metallic iron traces (as evidenced in figure 51) can be explained by the formation of wüstite as by-product during the process, which evolves at high temperatures to magnetite and metallic iron. ${ }^{49}$ 


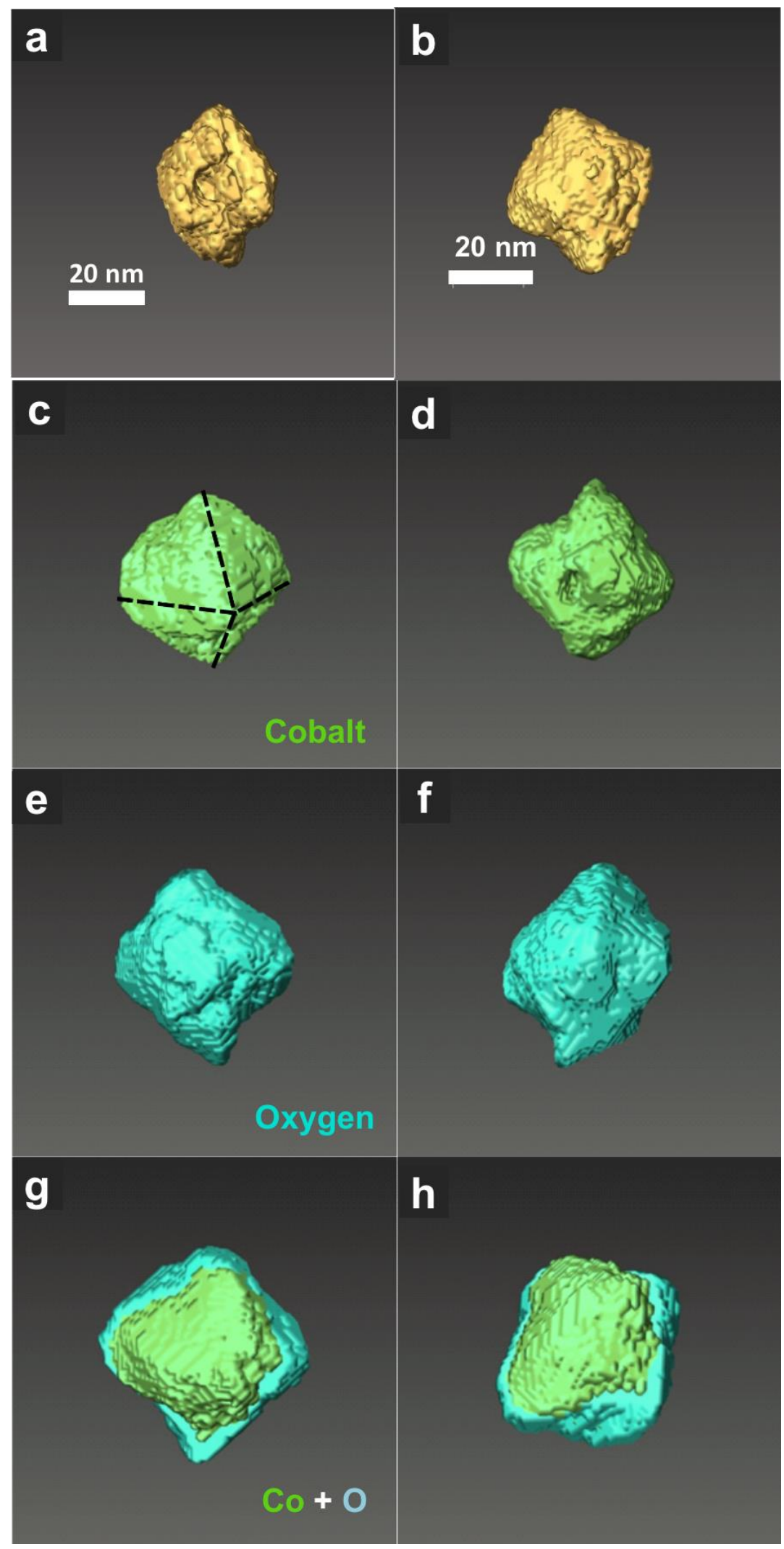

Figure 4. Representative HAADF tomography images ( $a$ and $b$ ). 3D tomography reconstruction of nanocrystals from the CoO@MFO sample, with EELS signal reconstruction for cobalt (c and d), oxygen (e and f), or both elements together ( $g$ and $h$ ) (cobalt in green and oxygen in cyan blue). 


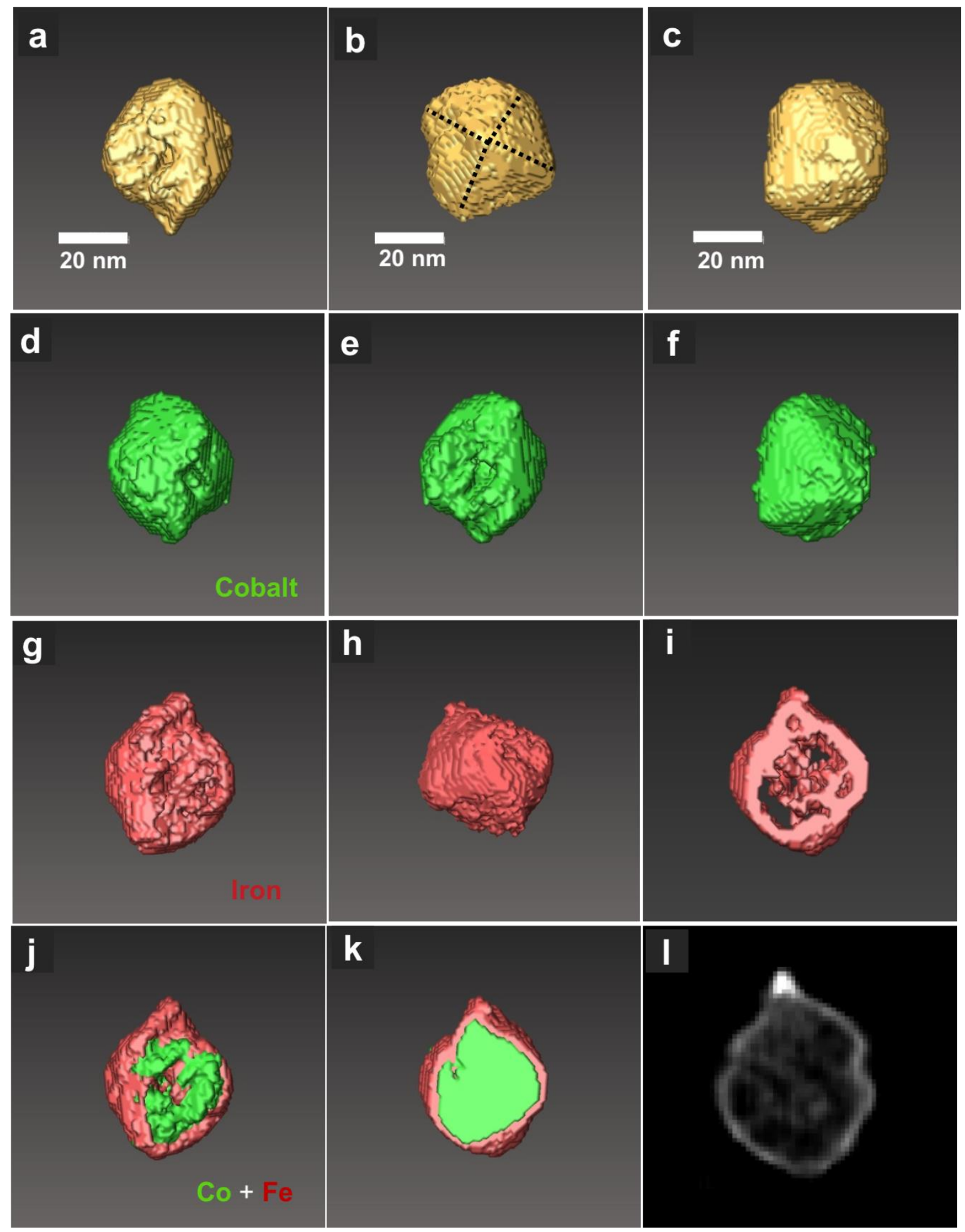

Figure 5. Representative HAADF tomography images (a, b and c). 3D tomography reconstruction of nanocrystals from the $\mathrm{CoO} @ \mathrm{CFO}$ sample, with EELS signal reconstruction for cobalt (d, e and f), iron (g, h and $\mathrm{i}$ ) and both elements together $(\mathrm{j}$ and $\mathrm{k})$ (cobalt in green and iron in red). In panels $\mathrm{i}$ and $\mathrm{j}$ the reconstruction has been cut in half to appreciate the inner features of the object. Iron intensity at the central slice of the reconstruction (1). 
Given the very low concentration of manganese in the CoO@MFO nanocrystals, an additional evaluation of the elemental distribution was also carried out by EELS point analyses together with further HRTEM studies. Figure 6 includes the summary of the analysis of a nanocrystal from the CoO@MFO sample, with a large cavity inside (see figure 6a) and with a core-shell structure (see figures $6 \mathrm{~b}$ and $6 \mathrm{~d}$ ). Figure $6 \mathrm{c}$ shows the corresponding fast Fourier transform (FFT), on which the indexation indicated in red was done on the basis of the spinel crystalline structure and the indexation in yellow was done on the basis of the $\mathrm{CoO}$ rock-salt crystalline structure, both indicating the [211] zone axis. The lack of evident extra spots or double diffraction spots in the FFT image can be explained if we assume a directed epitaxial growth of the mixed spinel onto the rock-salt crystalline structure. In this regard, figure $6 \mathrm{~d}$ includes a HRTEM image of the edge of this hollow nanoparticle which reflects this expected core-shell structure, clearly showing that there are two different crystalline phases (lattices), with the second one (the shell thickness is about $\sim 3.2 \mathrm{~nm}$ matching the 3D tomography results) grown driven by the $\{111\}$ surface facets of the initial cobalt oxide octahedron. This TEM analysis also reveals that the $\mathrm{Mn}_{\mathrm{x}} \mathrm{Fe}_{3-\mathrm{x}} \mathrm{O}_{4}$ grains have grown, guided by the lattice matching along the eight $\{111\}$ surface planes of the core, but leading to a fragmentation of the shell into multigrains. ${ }^{50}$ In this regard, the fact that every initial cobalt oxide core presents cracks up to the surface also helps promoting the formation of an ordered but grained structure, as shown in figure $6 \mathrm{~b}$. Furthermore, figures $6 \mathrm{e}$ and $6 \mathrm{f}$ show the EELS spectra spatially resolved after background subtraction at the $\mathrm{O}-\mathrm{K}, \mathrm{Mn}-\mathrm{L}_{2,3}, \mathrm{Fe}-\mathrm{L}_{2,3}$, and $\mathrm{Co}-\mathrm{L}_{2,3}$ edges. They were collected on different spots of the nanoscrystal shown in figure 6a, over the large region framed in green in the inset of figure 6e. Focusing first on the O-K edge (see a more detailed comparison in figure S3 in the SI), the fine structure can distinguish the different cobalt oxide phases present in the sample due to its sensitivity to the chemical environment. The intense and single peak at $535 \mathrm{eV}$, characteristic of the presence of $\mathrm{CoO},{ }^{45,51}$ and the $\mathrm{L}_{3} / \mathrm{L}_{2}$ ratio for the Co-L edge (also indicative of the cobalt valence state) ${ }^{51-54}$ point to the $\mathrm{CoO}$ as the main phase. However, the spectra shown in figure $6 \mathrm{f}$, collected with a $1 \mathrm{~nm}$ probe 
size from the red and blue spots shown in the HRTEM image in figure 6a, reflect a different composition at the core and the shell. Hence, the presence of Mn and Fe mainly at the external layer confirms the core-shell structure shown in the HRTEM analysis.

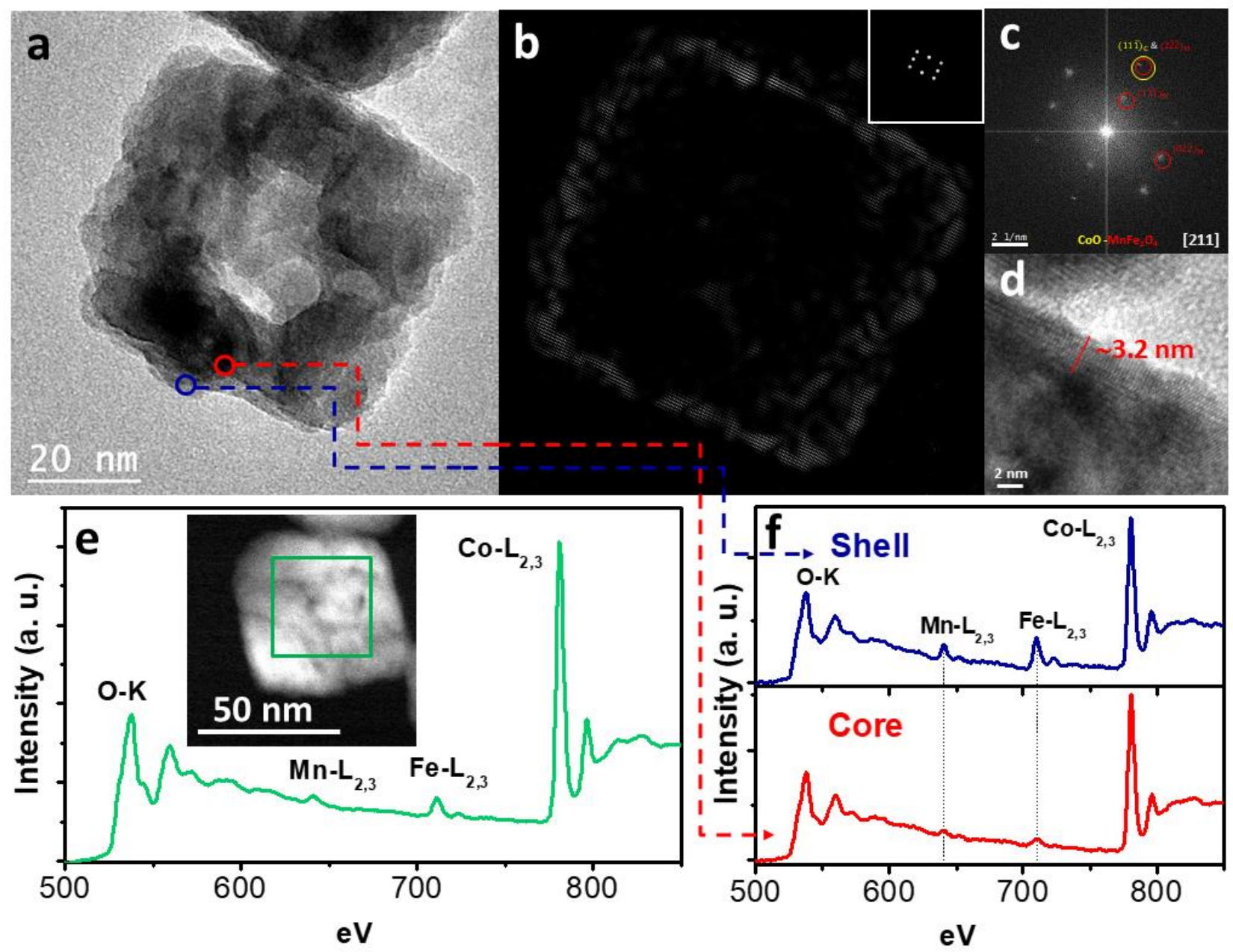

Figure 6. HRTEM image (a) and inverse Fourier filtered image using the frequencies that correspond to the spinel structure (b) of an individual octahedron from the $\mathrm{CoO} @ \mathrm{MFO}$ sample, reflecting a large cavity inside. Corresponding FFT obtained from the same nanocrystal reflecting the [211] zone axis (c). HRTEM at the edge of this nanocrystal, showing a core-shell structure, with an outer shell $\sim 3.2$ $n m$ thick (d). EELS spectra (e, f) recorded at different regions of the nanocrystal (green region of the STEM image in the inset of figure 6e and red and blue spots in the HRTEM image in figure 6a). 
To complete the characterization, figure 7 and table I include a summary of the magnetic behavior of the three samples considered. The temperature dependence of the magnetization under ZFC and FC conditions $\left(\mu_{0} \mathrm{H}=10 \mathrm{mT}\right.$ ) was measured, showing irreversibility between the ZFC and FC curves up to the highest measured temperature $(\mathrm{T}=325 \mathrm{~K})$, which is above the Néel temperature of $\mathrm{CoO}$ ( $\mathrm{T}_{\mathrm{N}} \sim 291 \mathrm{~K}$ for bulk, indicated in the ZFC-FC graphs with a vertical dotted line). Indeed, the CoO sample shows a very subtle peak in this region (indicated with a black arrow in figure $7 \mathrm{a}$, and clearly shown in the derivative of the temperature-dependent magnetization curve included in figure $S 4$, in the SI), related to its antiferromagnetic-paramagnetic transition. This transition can also be observed for the CoO@MFO sample (figure 7d, indicated with a blue arrow and in figure S4 in the SI), but screened for the $\mathrm{CoO} @ \mathrm{CFO}$ sample. At lower temperatures, additional transitions are present in the CoO sample, which can be attributed to the outer $\mathrm{Co}_{3} \mathrm{O}_{4}$ shell $\left(\mathrm{T}_{\mathrm{N}} \sim 40 \mathrm{~K}\right)$ or to a blocking temperature of smaller nanocrystals. Due to the presence of the ferrimagnetic ferrite components, the coated systems display much larger values of magnetization, with a noteworthy difference between the ZFC and FC curves throughout the whole range considered. As in the case of $\mathrm{CoO}$, the features observed at very low temperatures in these two samples are indicative of the presence of $\mathrm{Co}_{3} \mathrm{O}_{4}$ and smaller nanocrystallites.

The hysteresis loops from the three samples were registered at 10 and $325 \mathrm{~K}$, showing in the three cases the coexistence of a ferrimagnetic (hysteresis) and an antiferromagnetic contribution (linear response at high fields in the coated samples). The ferrimagnetic contribution is responsible for the increase in the values of maximum magnetization, from roughly $5.7 \mathrm{Am}^{2} / \mathrm{kg}$ in the non-coated sample to 40 and $80 \mathrm{Am}^{2} / \mathrm{kg}$ at $10 \mathrm{~K}$ in the $\mathrm{CoO} @ \mathrm{MFO}$ and $\mathrm{CoO} @ \mathrm{CFO}$ samples, respectively. The values of saturation magnetization upon subtraction of the linear antiferromagnetic contribution are 35 and $78 \mathrm{Am}^{2} / \mathrm{kg}$ at $10 \mathrm{~K}$, and 30 and $74 \mathrm{Am}^{2} / \mathrm{kg}$ at $325 \mathrm{~K}$ for the $\mathrm{CoO} @ \mathrm{MFO}$ and $\mathrm{CoO} @ \mathrm{CFO}$ samples, respectively. The field-dependent magnetization of the three samples was also registered at $10 \mathrm{~K}$ after field-cooling the samples. Figure S5 in the Supporting Information includes a comparison of the 
hysteresis loops of the three samples registered after ZFC and FC conditions (cooling from $340 \mathrm{~K}$ under an applied field of $5 \mathrm{~T}$ ), in order to obtain information of the interfaces between the different magnetic phases present in the nanocrystals. The FC hysteresis loops of all samples show horizontal and vertical shifts, with a shift along the field axis, defined by $\mathrm{H}_{\mathrm{E}}=\left(\mathrm{H}_{\mathrm{C}+}+\mathrm{H}_{\mathrm{C}-}\right) / 2$, besides an increase of the coercive field (summarized in Table I), all associated to the characteristic exchange bias effect associated to the ferri-antiferromagnetic interface. The initial $\mathrm{CoO}$ sample shows this shift in the negative field axis, with $\mu_{0} \mathrm{H}_{\mathrm{E}}=24.9 \mathrm{mT}$, which decreases to 7.6 and $5.5 \mathrm{mT}$ in the case of CoO@MFO and $\mathrm{CoO} @ \mathrm{CFO}$ samples, respectively. While the initial shift in the CoO sample can be attributed to an exchange coupling at the $\mathrm{CoO} / \mathrm{Co}_{3} \mathrm{O}_{4}$ interface, ${ }^{46}$ the decrease in $\mu_{0} \mathrm{H}_{\mathrm{E}}$ registered upon coating can be ascribed to a disruption of the interfaces playing a role. This is indeed more pronounced in the case of the CoO@CFO sample, as evidenced by the larger number of voids within the sample and the more accentuated intermixing process at the new interface established.
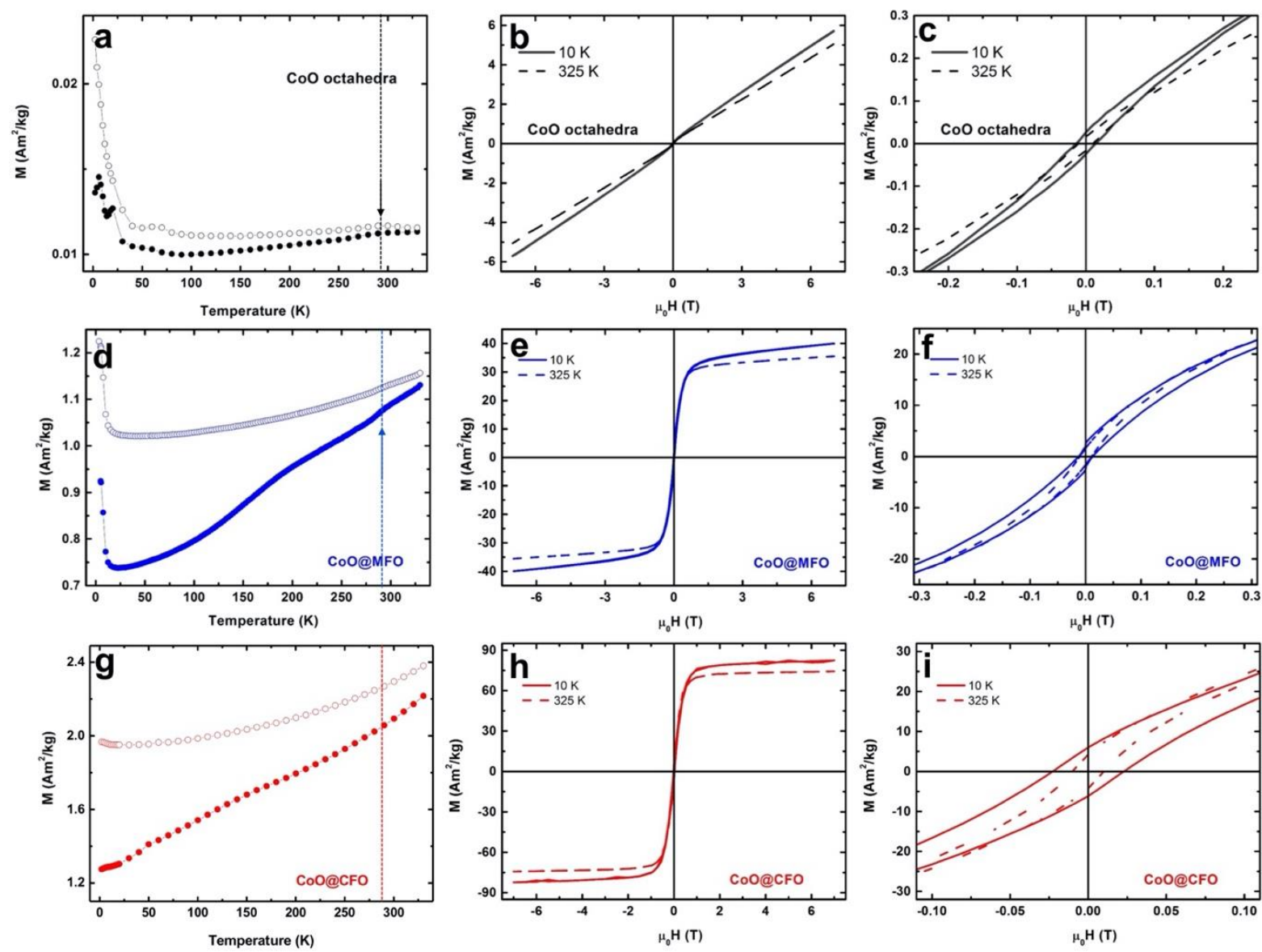
Figure 7. ZFC and FC curves measured applying a $10 \mathrm{mT}$ magnetic field (a, d and g), magnetic hysteresis loops measured at 10 and $325 \mathrm{~K}(\mathrm{~b}, \mathrm{e}, \mathrm{h})$ and corresponding close-up at low fields (c, $\mathrm{f}$ and i) of the $\mathrm{CoO}$ (black), $\mathrm{CoO} @ \mathrm{MFO}$ (blue) and $\mathrm{CoO} @ \mathrm{CFO}$ (red) samples, respectively.

Table I. Summary of magnetic parameters of the $\mathrm{CoO}, \mathrm{CoO} @ \mathrm{MFO}$ and $\mathrm{CoO} @ \mathrm{CFO}$ systems. The saturation magnetization values were obtained upon subtraction of the linear antiferromagnetic contribution.

\begin{tabular}{ccccccc}
\hline & \multicolumn{2}{c}{$\mathbf{M}_{\mathbf{S}}\left(\mathbf{A m} \mathbf{m}^{2} / \mathbf{k g}\right)$} & $\mu_{0} \mathbf{H}_{\mathbf{C}}(\mathbf{m T})(\mathbf{Z F C})$ & $\begin{array}{c}\mu_{0} \mathbf{H}_{\mathbf{C}}(\mathbf{m T}) \\
(\mathbf{F C})\end{array}$ & $\mu_{0} \mathbf{H}_{\mathrm{E}}(\mathbf{m T})$ \\
\cline { 2 - 7 } Sample & $\mathrm{T}=325 \mathrm{~K}$ & $\mathrm{~T}=10 \mathrm{~K}$ & $\mathrm{~T}=325 \mathrm{~K}$ & $\mathrm{~T}=10 \mathrm{~K}$ & $\mathrm{~T}=10 \mathrm{~K}$ & $\mathrm{~T}=10 \mathrm{~K}$ \\
\hline $\mathbf{C o O}$ & 0.1 & 0.4 & 10.3 & 13.9 & 16.9 & -24.9 \\
\hline CoO@MFO & 30 & 35 & 10.5 & 12.6 & 19.7 & -7.6 \\
\hline CoO@CFO & 74 & 78 & 10.1 & 22.8 & 28.3 & -5.5 \\
\hline
\end{tabular}

In order to correlate the magnetization values with the morphology attained, we have calculated the expected maximum magnetization (at $10 \mathrm{~K}$ ) of an ideal $\mathrm{CoO}$ octahedral particle with a $50 \mathrm{~nm}$ edge (considering a maximum value of magnetization of $5.7 \mathrm{Am}^{2} / \mathrm{kg}$, as registered experimentally), coated with a perfect $3 \mathrm{~nm}$-thick shell of stoichiometric $\mathrm{MnFe}_{2} \mathrm{O}_{4}$ or $\mathrm{CoFe}_{2} \mathrm{O}_{4}$, (considering saturation magnetizations of 112 and $90 \mathrm{Am}^{2} / \mathrm{kg}$, respectively), ${ }^{55}$ using tabulated mass densities and neglecting any other contribution to the magnetization. Taking this ideal morphology into account, we obtain values of maximum magnetization of $32 \mathrm{Am}^{2} / \mathrm{kg}$ and $27 \mathrm{Am}^{2} / \mathrm{kg}$ for perfect $\mathrm{CoO} @ \mathrm{MFO}$ and CoO@CFO core-shell octahedra. These values are far below the experimental ones obtained at $10 \mathrm{~K}$ and applying a $7 \mathrm{~T}$ magnetic field. Going one step further, we proceed with the same calculation, but considering the average shrinkage observed experimentally and a theoretical $10 \%$ or $15 \%$ of voids in the total volume of the $35.9 \mathrm{~nm} \mathrm{CoO}$ belonging to the CoO@ MFO or of the $31.3 \mathrm{~nm} \mathrm{CoO}$ belonging to the $\mathrm{CoO} @ \mathrm{CFO}$, respectively. This way we also assume the formation of an average $3 \mathrm{~nm}$ thick 
perfect shell of $\mathrm{Mn}_{0.4} \mathrm{Fe}_{2.6} \mathrm{O}_{4}\left(\mathrm{M}_{\mathrm{S}}=103.6 \mathrm{Am}^{2} / \mathrm{kg}\right)$ or $\mathrm{CoFe}_{2} \mathrm{O}_{4}\left(\mathrm{MS}_{\mathrm{S}}=90 \mathrm{Am}^{2} / \mathrm{kg}\right)$. With this situation into account, having considered the more important shrinkage in the final size, the larger dimensions of the hollow cavities inside the nanocrystals of the $\mathrm{CoO} @ \mathrm{CFO}$ sample, and iterating the contribution from metallic iron to approach the experimental values (contribution of $\sim 3$ vol.\%), maximum magnetization values of $40 \mathrm{Am}^{2} / \mathrm{kg}$ for the two $\mathrm{CoO} @ \mathrm{MFO}$ and $\mathrm{CoO} @ \mathrm{CFO}$ samples were obtained. Such values are close to the experimental data obtained for the $\mathrm{CoO} @ \mathrm{MFO}$ but far below the value measured for the $\mathrm{CoO} @ \mathrm{CFO}$ sample, which led us to think of a different reason besides the presence of metallic iron for the magnetic moment enhancement in this sample, as actually including, according to the XRD intensities, an even lower amount of the metal in this sample.

To shed light on this and summarizing the characterization section, we can state that the core-shell $\mathrm{CoO} @ \mathrm{MFe}_{2} \mathrm{O}_{4}(\mathrm{M}$ : $\mathrm{Mn}$ or $\mathrm{Co}$ ) nanoparticles undergo a restructuring-hollowing process by which there is an important shrinkage in the final size and a significant increase in the dimension of the hollow cavities inside the nanocrystals. In this manner, the morphological evolution of the nanoparticles is the result of solid-solid diffusion processes by which inhomogeneous mixed oxides are formed. Accordingly, the nanocrystals in the $\mathrm{CoO} @ \mathrm{MFO}$ sample include $\mathrm{CoO}, \mathrm{Co}_{3} \mathrm{O}_{4}$ and $\mathrm{Mn}$ and $\mathrm{Co}$-doped $\mathrm{Fe}_{3} \mathrm{O}_{4}$, with a negative gradient in the cobalt doping as moving in the outward direction and the presence of residual metallic iron. Analogously, the nanocrystals from the CoO@CFO sample include $\mathrm{CoO}$ and $\mathrm{Co}_{3} \mathrm{O}_{4}$ (residual), Co-doped $\mathrm{CoFe}_{2} \mathrm{O}_{4}$ (cobalt-rich layer) and Co-doped $\mathrm{Fe}_{3} \mathrm{O}_{4}$ (ironrich layer) with some residual metallic iron, also following the outward direction. The presence of a cobalt-rich spinel is indeed corroborated by the soft behavior observed for this sample at low temperature, with a coercivity value of $\mu_{0} \mathrm{H}_{\mathrm{C}} \sim 22 \mathrm{mT}$ (see summary of magnetic parameters of the three samples in table I, in the SI), a rather small value if one takes into account the hard magnetic behavior displayed by the stoichiometric inverse $\mathrm{CoFe}_{2} \mathrm{O}_{4} \cdot{ }^{56}$ Furthermore, this small value of coercivity confirms as well the residual amount of metallic iron. The origin of such soft behavior can be ascribed to the redistribution of $\mathrm{Co}^{2+}$ ions among the octahedral/tetrahedral sites and the $\mathrm{Fe} / \mathrm{Co}$ 
ratio gradient, which change the effective magnetic anisotropy of the system due to $\mathrm{Co}^{2+}$ ions in the trigonal-field at the octahedral sites.

To understand this final morphology attained and the disposition of stratified layers of different oxides in the final nanocrystals, with a magnetically dominant spinel structure in view of the magnetic properties they display, different aspects must be taken into account. First, this final distribution is postulated to appear once the growth process has finished but the system has not attained its thermodynamic stability yet. At this point, the surface energy of a material at the nanoscale can alter its free energy, such that another material with the same elements but different stoichiometry and crystalline structure is formed, driven by a thermodynamic crossover in phase stability. ${ }^{57}$ Such phase reconfiguration is indeed favored given the relatively high temperature of the synthetic process and assisted by effects stemming from the nanometer size. In this regard, a chemomechanical model of void formation has been recently reported, by which the mechanical constraint of an oxide layer during a delithiation process causes nanoparticles to form voids or to allow for particle shrinkage without void formation, depending on the particle size. ${ }^{23}$ Analogously, in our case, as $\mathrm{Co}^{2+}$ cations diffuse out from the core, the $\mathrm{CoO}$ phase shrinks in volume, exerting a compressive stress on the outer ferrite layer. In response, the ferrite layer applies increasing tension to the core, with a situation similar to a pressure vessel with negative pressure, in the early stages of the process. ${ }^{23}$ Attending to this model, the buckling of the ferrite layer to allow for particle shrinkage is more favored, since relatively large particles require a greater strain energy to create new voids. Moreover, the assynthesized cobalt oxide octahedra are already endowed with voids and cracks (see TEM image in figure $1 b),{ }^{58}$ which promote simultaneously with the particle shrinkage, the hollowing process. From the point of view of redox processes, galvanic reactions may also take place but to a much lesser extent. Indeed, the ferrite oxidation reactions are cation diffusion-limited under oxygen rich environments, because of the larger concentration of cationic vacancies with respect to anionic ones (oxygen) in the crystalline structure. ${ }^{31,59,60}$ In this context, the crystal field theory has been used to 
explain relative cationic diffusion preferences, taking into account the degree of tetrahedral/octahedral site preference and the consequent degree of inversion. ${ }^{61}$ For example, activation energies for the vacancy mediated diffusion of cations in different ferrites, considering atomic and spin configurations were calculated for both normal and inverse configurations in the crystalline structure and the magnetic behavior. ${ }^{62}$ According to such calculations, the cationic vacancies do not only occupy preferentially octahedral over tetrahedral sites but also indicate that cation diffusion through ferrites is dominated by octahedral-octahedral hops, ${ }^{63}$ limiting vacancy exchange between the two sites. This reaction pathway for octahedral-octahedral migration considers activation energies resulting from the occupation and energies of the $t_{2 g}$ and $e_{g}$ states of the active cation, by which the final magnetic state and the magnetic properties are governed. Along these lines, a progressive doping and redistribution of $\mathrm{Co}^{2+}$ cations diffusing out from the initial cobalt oxide core considering this octahedral-octahedral migration can explain the formation of the mixed ferrites and the final magnetic properties (see schemes of the interfaces between oxides before and after the intermixing for the two samples in figure S6, in the SI). For the CoO@MFO sample, the fact that tetrahedral sites are preferentially occupied by $\mathrm{Mn}^{2+}$ and $\mathrm{Fe}^{3+}$ cations in the spinel structure ${ }^{64}$ reinforces the hypothesis of the $\mathrm{Co}^{2+}$ cations diffusing out to occupy octahedral sites, offering a prevalent $\mathrm{Mn}$ and Co-doped magnetite phase. However, for the $\mathrm{CoO} @ \mathrm{CFO}$ sample, another aspect to take into account is the fact that both $\mathrm{CoO}-\mathrm{Co}_{3} \mathrm{O}_{4}$ and $\mathrm{Co}_{3} \mathrm{O}_{4}-\mathrm{MFe}_{2} \mathrm{O}_{4}$ interfaces have been reported to be epitaxially matched at the (111) facets of the fcc sublattice of host $\mathrm{O}^{2-}$ ions, ${ }^{46,65}$ since the small bulk lattice mismatch between these two lattices can be accomodated by strain. $\mathrm{CoFe}_{2} \mathrm{O}_{4}$ was demonstrated to accommodate this epitaxial stress by a continuous migration of $\mathrm{Co}^{2+}$ from the octahedral to tetrahedral sites, resulting in important changes in the magnetic anisotropy. ${ }^{15}$ With a redistribution of $\mathrm{Co}^{2+}$ ions to the tetrahedral sites, we can recalculate the net magnetic moment per formula unit of a spinel ferrite at $0 \mathrm{~K}$, using Néel's two sublattice model.$^{55,66} \mathrm{In}$ this model, the net magnetization of the cobalt ferrite with no inversion degree, that is, with the normal spinel structure 
$\left(\mathrm{Co}^{2+}\left[\mathrm{Fe}^{3+}\right]_{2} \mathrm{O}_{4}\right)$ instead of the inverse one $\left(\mathrm{Fe}^{3+}\left[\mathrm{Co}^{2+} \mathrm{Fe}^{3+}\right] \mathrm{O}_{4}\right)$, increases up to $7 \mu_{\mathrm{B}}$ in comparison to the $3 \mu_{\mathrm{B}}$ for the inverse structure. Indeed, a favored redistribution of $\mathrm{Co}^{2+}$ ions to the tetrahedral sites, as reported in thin films, driven by the strain imposed from the cobalt oxide layer below and helped by increasing the temperature, ${ }^{15,67}$ explains the reduced coercivity and the enhanced magnetization measured in the case of the $\mathrm{CoO} @ \mathrm{CFO}$ sample.

\section{Conclusions}

In summary, the mechanism by which attaining octahedrals of mixed oxides starting from $\mathrm{CoO} @ \mathrm{MFe}_{2} \mathrm{O}_{4}(\mathrm{M}: \mathrm{Mn}, \mathrm{Co})$ core@ shell octahedra is detailed, taking a solid-solid diffusion process into account. This postulated mechanism explains the fact that the hollow/porous nanostructures present a stratified morphology with a magnetically prevailing spinel crystalline structure, on which a progressive doping and redistribution of $\mathrm{Co}^{2+}$ cations diffusing out from the cobalt oxide initial core determines the final magnetic properties. The fact that tetrahedral sites of the spinel structure are preferentially occupied by $\mathrm{Mn}^{2+}$ cations forces the $\mathrm{Co}^{2+}$ cations diffusing out to occupy octahedral sites, offering a prevalent $\mathrm{Mn}$ and Co-doped magnetite phase in the $\mathrm{CoO}-\mathrm{Mn}_{0.4} \mathrm{Co}_{1.8} \mathrm{Fe}_{0.8} \mathrm{O}_{4}$ sample. Alternatively, in the $\mathrm{CoO}-\mathrm{Co}_{1.9} \mathrm{Fe}_{1.1} \mathrm{O}_{4}$ sample the $\mathrm{Co}^{2+}$ cations diffusing out can occupy tetrahedral sites, promoted by the strain generated at the ferrite layers closer to the interfase. In this situation, a normal instead of an inverse cobalt ferrite is attained as the prevalent phase in the final nanostructures, promoting therefore the enhanced magnetization registered. In both cases, the use of interfaces as the starting point in preparative solid-state chemistry is demonstrated, providing an unprecedented degree of control when referred to the magnetic properties of these transition metal oxides at the nanoscale, of which, catalytic, biomedical and energy storage applications, in addition to spintronic applications, can benefit.

\section{Acknowledgments}


M. T.-A., B. R.-M. And V. S. acknowledge financial support from the Xunta de Galicia (Regional Government, Spain) under the project ED431C 2016-034 and from the Spanish Ministerio de Economía y Competitividad under project CTM2017-84050-R. M. T.-A. acknowledges financial support from the Xunta de Galicia (Regional Government, Spain) under grant 2017 ED481A. P. T., S. E. and F. P. acknowledge Spanish Government for projects MAT2016-79455-P and Research Network RED2018-102609-T of Ministerio de Ciencia, Innovación y Universidades. The authors thank M. A. Ramos-Docampo for useful discussions about galvanic reactions and R. MariñoFernández for the initial synthetic experiments.

\section{Supporting Information}

Raman spectra registered from two different spots in the CoO@MFO sample, X-ray powder diffractograms, oxygen K-edge of the EEL spectra recorded in the $\mathrm{CoO} @ \mathrm{MFO}$ sample, derivatives of the ZFC temperature-dependent magnetization and ZFC and FC hysteresis loops measured at $10 \mathrm{~K}$.

\section{References}

(1) López-Ortega, A.; Estrader, M.; Salazar-Alvarez, G.; Roca, A. G.; Nogués, J. Applications of Exchange Coupled Bi-Magnetic Hard/Soft and Soft/Hard Magnetic Core/Shell Nanoparticles. Phys. Rep. 2015, 553, 1-32. https://doi.org/10.1016/j.physrep.2014.09.007.

(2) Hu, H.; Guan, B.; Xia, B.; Lou, X. W. Designed Formation of Co3O4/NiCo2O4 DoubleShelled Nanocages with Enhanced Pseudocapacitive and Electrocatalytic Properties. J. Am. Chem. Soc. 2015, 137, 5590-5595. https://doi.org/10.1021/jacs.5b02465.

(3) Peng, S.; Gong, F.; Li, L.; Yu, D.; Ji, D.; Zhang, T.; Hu, Z.; Zhang, Z.; Chou, S.; Du, Y.; Ramakrishna, S. Necklace-like Multishelled Hollow Spinel Oxides with Oxygen Vacancies for Efficient Water Electrolysis. J. Am. Chem. Soc. 2018, 140, 13644-13653. https://doi.org/10.1021/jacs.8b05134.

(4) Jang, B.; Park, M.; Chae, O. B.; Park, S.; Kim, Y.; Oh, S. M.; Piao, Y.; Hyeon, T. Direct 
Synthesis of Self-Assembled Ferrite/Carbon Hybrid Nanosheets for High Performance Lithium-Ion Battery Anodes. J. Am. Chem. Soc. 2012, 134, 15010-15015. https://doi.org/10.1021/ja305539r.

(5) Muhich, C. L.; Evanko, B. W.; Weston, K. C.; Lichty, P.; Liang, X.; Martinek, J.; Musgrave, C. B.; Weimer, A. W. Efficient Generation of H2 by Splitting Water with an Isothermal Redox Cycle. Science (80-. ). 2013, 341, 540-542. https://doi.org/10.1126/science.1239454.

(6) Bayliss, R. D.; Key, B.; Sai Gautam, G.; Canepa, P.; Kwon, B. J.; Lapidus, S. H.; Dogan, F.; Adil, A. A.; Lipton, A. S.; Baker, P. J.; Ceder, G.; Vaughey, J. T.; Cabana, J. Probing Mg Migration in Spinel Oxides. Chem. Mater. 2020, 32, 663-670. https://doi.org/10.1021/acs.chemmater.9b02450.

(7) Ramos, A. V.; Santos, T. S.; Miao, G. X.; Guittet, M. J.; Moussy, J. B.; Moodera, J. S. Influence of Oxidation on the Spin-Filtering Properties of $\mathrm{CoFe}_{2} \mathrm{O}_{4}$ and the Resultant Spin Polarization. Phys. Rev. B. 2008, 78, 180402. https://doi.org/10.1103/PhysRevB.78.180402.

(8) Lukashev, P. V.; Burton, J. D.; Smogunov, A.; Velev, J. P.; Tsymbal, E. Y. Interface States in CoFe2O4 Spin-Filter Tunnel Junctions. Phys. Rev. B. 2013, 88 (13), 134430. https://doi.org/10.1103/PhysRevB.88.134430.

(9) Carta, D.; Casula, M. F.; Falqui, A.; Loche, D.; Mountjoy, G.; Sangregorio, C.; Corrias, A. A Structural and Magnetic Investigation of the Inversion Degree in Ferrite Nanocrystals $\mathrm{MFe}_{2} \mathrm{O}_{4}(\mathrm{M}=\mathrm{Mn}, \mathrm{Co}, \mathrm{Ni})$. J. Phys. Chem. C 2009, 113, 8606-8615. https://doi.org/10.1021/jp901077c.

(10) Peddis, D.; Yaacoub, N.; Ferretti, M.; Martinelli, A.; Piccaluga, G.; Musinu, A.; Cannas, C.; Navarra, G.; Greneche, J. M.; Fiorani, D. Cationic Distribution and Spin Canting in $\mathrm{CoFe}_{2} \mathrm{O}_{4}$ Nanoparticles. J. Phys. Condens. Matter 2011, 23, 426004. https://doi.org/10.1088/0953$8984 / 23 / 42 / 426004$.

(11) Dionne, G. F. Magnetic Oxides; Springer Science and Business Media: Boston, 2009. 
https://doi.org/10.1007/978-1-4419-0054-8.

(12) Huijben, M.; Martin, L. W.; Chu, Y. H.; Holcomb, M. B.; Yu, P.; Rijnders, G.; Blank, D. H. A.; Ramesh, R. Critical Thickness and Orbital Ordering in Ultrathin $\mathrm{La}_{0.7} \mathrm{Sr}_{0.3} \mathrm{MnO}_{3}$ Films. Phys. Rev. B - Condens. Matter Mater. Phys. 2008, 78, 094413.

https://doi.org/10.1103/PhysRevB.78.094413.

(13) Moyer, J. A.; Vaz, C. A. F.; Kumah, D. P.; Arena, D. A.; Henrich, V. E. Enhanced Magnetic Moment in Ultrathin Fe-Doped CoFe $2 \mathrm{O} 4$ Films. Phys. Rev. B. 2012, 86, 174404. https://doi.org/10.1103/PhysRevB.86.174404.

(14) Rigato, F.; Geshev, J.; Skumryev, V.; Fontcuberta, J. The Magnetization of Epitaxial Nanometric CoFe2O4 (001) Layers. J. Appl. Phys. 2009, 106, 113924. https://doi.org/10.1063/1.3267873.

(15) Ferreiro-Vila, E.; Iglesias, L.; Lucas Del Pozo, I.; Varela-Dominguez, N.; Bui, C. T.; RivasMurias, B.; Vila-Fungueiriño, J. M.; Jimenez-Cavero, P.; Magen, C.; Morellon, L.; Pardo, V.; Rivadulla, F. Apparent Auxetic to Non-Auxetic Crossover Driven by $\mathrm{Co}^{2+}$ Redistribution in $\mathrm{CoFe}_{2} \mathrm{O}_{4}$ Thin Films. APL Mater. 2019, 7, 031109. https://doi.org/10.1063/1.5087559.

(16) Testa-Anta, M.; Rivas-Murias, B.; Salgueiriño, V. Spin Frustration Drives Exchange Bias Sign Crossover in $\mathrm{CoFe}_{2} \mathrm{O}_{4}-\mathrm{Cr}_{2} \mathrm{O}_{3}$ Nanocomposites. Adv. Funct. Mater. 2019, 29 (36), 1900030. https://doi.org/10.1002/adfm.201900030.

(17) Zubko, P.; Gariglio, S.; Gabay, M.; Ghosez, P.; Triscone, J. M. Interface Physics in Complex Oxide Heterostructures. Annual Review of Condensed Matter Physics. 2011, 141-165. https://doi.org/10.1146/annurev-conmatphys-062910-140445.

(18) Bianchini, M.; Wang, J.; Clément, R. J.; Ouyang, B.; Xiao, P.; Kitchaev, D.; Shi, T.; Zhang, Y.; Wang, Y.; Kim, H.; Zhang, M.; Bai, J.; Wang, F.; Sun, W.; Ceder, G. The Interplay between Thermodynamics and Kinetics in the Solid-State Synthesis of Layered Oxides. Nat. Mater. 2020, 19, 1088-1095. https://doi.org/10.1038/s41563-020-0688-6. 
(19) Kohlmann, H. Looking into the Black Box of Solid-State Synthesis. European Journal of Inorganic Chemistry. 2019, 39-40, 4174-4180. https://doi.org/10.1002/ejic.201900733.

(20) López-Ortega, A.; Roca, A. G.; Torruella, P.; Petrecca, M.; Estradé, S.; Peiró, F.; Puntes, V.; Nogués, J. Galvanic Replacement onto Complex Metal-Oxide Nanoparticles: Impact of Water or Other Oxidizers in the Formation of Either Fully Dense Onion-like or Multicomponent Hollow $\mathrm{MnO}_{\mathrm{x}} / \mathrm{FeO}_{\mathrm{x}}$ Structures. Chem. Mater. 2016, 28, 8025-8031. https://doi.org/10.1021/acs.chemmater.6b03765.

(21) Yu, L.; Hu, H.; Wu, H. Bin; Lou, X. W. D. Complex Hollow Nanostructures: Synthesis and Energy-Related Applications. Advanced Materials. 2017, 29, 1604563. https://doi.org/10.1002/adma.201604563.

(22) Wei, R.; Cai, Z.; Ren, B. W.; Li, A.; Lin, H.; Zhang, K.; Chen, H.; Shan, H.; Ai, H.; Gao, J. Biodegradable and Renal-Clearable Hollow Porous Iron Oxide Nanoboxes for in Vivo Imaging. Chem. Mater. 2018, 30, 7950-7961. https://doi.org/10.1021/acs.chemmater.8b03564.

(23) Boebinger, M. G.; Yarema, O.; Yarema, M.; Unocic, K. A.; Unocic, R. R.; Wood, V.; McDowell, M. T. Spontaneous and Reversible Hollowing of Alloy Anode Nanocrystals for Stable Battery Cycling. Nat. Nanotechnol. 2020, 15, 475-481. https://doi.org/10.1038/s41565-020-0690-9.

(24) Vaz, B.; Salgueiriño, V.; Pérez-Lorenzo, M.; Correa-Duarte, M. A. Enhancing the Exploitation of Functional Nanomaterials through Spatial Confinement: The Case of Inorganic Submicrometer Capsules. Langmuir 2015, 31, 8745-8755. https://doi.org/10.1021/acs.langmuir.5b00098.

(25) Kirkendall, E. O. Diffusion of Zinc in Alpha Brass. Trans. Am. Inst. Min. Metall. Eng. 1942, 147, 104-109.

(26) A.D. Smigelkas; E.O. Kirkendall. Zinc Diffusion in Alpha Brass. Trans. AIME 1947, 171, 
$130-142$.

(27) Yin, Y.; Rioux, R. M.; Erdonmez, C. K.; Hughes, S.; Somorjal, G. A.; Alivisatos, A. P. Formation of Hollow Nanocrystals Through the Nanoscale Kirkendall Effect. Science (80-. ). 2004, 304, 711-714. https://doi.org/10.1126/science.1096566.

(28) Wang, W.; Dahl, M.; Yin, Y. Hollow Nanocrystals through the Nanoscale Kirkendall Effect. Chemistry of Materials. 2013, 25, 1179-1189. https://doi.org/10.1021/cm3030928.

(29) Oh, M. H.; Yu, T.; Yu, S. H.; Lim, B.; Ko, K. T.; Willinger, M. G.; Seo, D. H.; Kim, B. H.; Cho, M. G.; Park, J. H.; Kang, K.; Sung, Y. E.; Pinna, N.; Hyeon, T. Galvanic Replacement Reactions in Metal Oxide Nanocrystals. Science. 2013, 340 (6135), 964-968. https://doi.org/10.1126/science.1234751.

(30) Gusak, A. M.; Zaporozhets, T. V.; Lyashenko, Y. O.; Kornienko, S. V.; Pasichnyy, M. O.; Shirinyan, A. S. Diffusion-Controlled Solid State Reactions: In Alloys, Thin Films and Nanosystems; Wiley-VCH, 2010.

(31) Lu, F. H.; Dieckmann, R. Point Defects and Cation Tracer Diffusion in (Co, Fe, Mn)3- $\Delta \mathrm{O} 4$ Spinels: I. Mixed Spinels $\left(\mathrm{Co}_{\mathrm{x}} \mathrm{Fe}_{2 \mathrm{y}} \mathrm{Mn}_{\mathrm{y}}\right)_{3-\delta} \mathrm{O}_{4}$. Solid State Ionics 1992, 53-56 (PART 1), 290302. https://doi.org/10.1016/0167-2738(92)90392-3.

(32) Limpert, E.; Stahel, W. A.; Abbt, M. Log-Normal Distributions across the Sciences: Keys and Clues. Bioscience 2001, 51, 341-352. https://doi.org/10.1641/00063568(2001)051[0341:LNDATS]2.0.CO;2.

(33) Moon, G. D.; Ko, S.; Min, Y.; Zeng, J.; Xia, Y.; Jeong, U. Chemical Transformations of Nanostructured Materials. Nano Today 2011, 6, 186-203. https://doi.org/10.1016/j.nantod.2011.02.006.

(34) Anderson, B. D.; Tracy, J. B. Nanoparticle Conversion Chemistry: Kirkendall Effect, Galvanic Exchange, and Anion Exchange. Nanoscale. Royal Society of Chemistry 2014, pp 12195-12216. https://doi.org/10.1039/c4nr02025a. 
(35) Testa-Anta, M.; Ramos-Docampo, M. A.; Comesaña-Hermo, M.; Rivas-Murias, B.; Salgueiriño, V. Raman Spectroscopy to Unravel the Magnetic Properties of Iron Oxide Nanocrystals for Bio-Related Applications. Nanoscale Adv. 2019, 1, 2086-2103. https://doi.org/10.1039/c9na00064j.

(36) Rivas-Murias, B.; Salgueiriño, V. Thermodynamic $\mathrm{CoO}-\mathrm{Co}_{3} \mathrm{O}_{4}$ Crossover Using Raman Spectroscopy in Magnetic Octahedron-Shaped Nanocrystals. J. Raman Spectrosc. 2017, 48 (6), 837-841. https://doi.org/10.1002/jrs.5129.

(37) Melendres, C. A.; Xu, S.; Tani, B. A Laser Raman Spectroscopic Study of Anodic Corrosion Films on Silver and Copper. J. Electroanal. Chem. 1984, 162, 343-349. https://doi.org/10.1016/S0022-0728(84)80177-1.

(38) Ravindra, A. V.; Behera, B. C.; Padhan, P. Laser Induced Structural Phase Transformation of Cobalt Oxides Nanostructures. J. Nanosci. Nanotechnol. 2014, 14, 5591-5595. https://doi.org/10.1166/jnn.2014.9023.

(39) White, W. B.; DeAngelis, B. A. Interpretation of the Vibrational Spectra of Spinels. Spectrochim. Acta Part A Mol. Spectrosc. 1967, 23, 985-995. https://doi.org/10.1016/05848539(67)80023-0.

(40) Verble, J. L. Temperature-Dependent Light-Scattering Studies of the Verwey Transition and Electronic Disorder in Magnetite. Phys. Rev. B 1974, 9, 5236-5248. https://doi.org/10.1103/PhysRevB.9.5236.

(41) Cynn, H.; Sharma, S. K.; Cooney, T. F.; Nicol, M. High-Temperature Raman Investigation of Order-Disorder Behavior in the $\mathrm{MgAl}_{2} \mathrm{O}_{4}$ Spinel. Phys. Rev. B 1992, 45, 500-502. https://doi.org/10.1103/PhysRevB.45.500.

(42) D’Ippolito, V.; Andreozzi, G. B.; Bersani, D.; Lottici, P. P. Raman Fingerprint of Chromate, Aluminate and Ferrite Spinels. J. Raman Spectrosc. 2015, 46, 1255-1264. https://doi.org/10.1002/jrs.4764. 
(43) Shebanova, O. N.; Lazor, P. Raman Spectroscopic Study of Magnetite $\left(\mathrm{FeFe}_{2} \mathrm{O}_{4}\right)$ : A New Assignment for the Vibrational Spectrum. J. Solid State Chem. 2003, 174, 424-430. https://doi.org/10.1016/S0022-4596(03)00294-9.

(44) Iliev, M. N.; Mazumdar, D.; Ma, J. X.; Gupta, A.; Rigato, F.; Fontcuberta, J. Monitoring BSite Ordering and Strain Relaxation in $\mathrm{NiFe}_{2} \mathrm{O}_{4}$ Epitaxial Films by Polarized Raman Spectroscopy. Phys. Rev. B - Condens. Matter Mater. Phys. 2011, 83, 014108. https://doi.org/10.1103/PhysRevB.83.014108.

(45) Fontaíña-Troitiño, N.; Liébana-Viñas, S.; Rodríguez-González, B.; Li, Z. A.; Spasova, M.; Farle, M.; Salgueiriño, V. Room-Temperature Ferromagnetism in Antiferromagnetic Cobalt Oxide Nanooctahedra. Nano Lett. 2014, 14, 640-647. https://doi.org/10.1021/n14038533.

(46) Li, Z. A.; Fontaína-Troitiño, N.; Kovács, A.; Liébana-Viñas, S.; Spasova, M.; DuninBorkowski, R. E.; Müller, M.; Doennig, D.; Pentcheva, R.; Farle, M.; Salgueiriño, V. Electrostatic Doping as a Source for Robust Ferromagnetism at the Interface between Antiferromagnetic Cobalt Oxides. Sci. Rep. 2015, 5, 1-6. https://doi.org/10.1038/srep07997.

(47) Chandramohan, P.; Srinivasan, M. P.; Velmurugan, S.; Narasimhan, S. V. Cation Distribution and Particle Size Effect on Raman Spectrum of $\mathrm{CoFe}_{2} \mathrm{O}_{4}$. J. Solid State Chem. 2011, 184, 89-96. https://doi.org/10.1016/j.jssc.2010.10.019.

(48) Bahlawane, N.; Ngamou, P. H. T.; Vannier, V.; Kottke, T.; Heberle, J.; Kohse-Höinghaus, K. Tailoring the Properties and the Reactivity of the Spinel Cobalt Oxide. Phys. Chem. Chem. Phys. 2009, 11, 9224-9232. https://doi.org/10.1039/b910707j.

(49) Testa-Anta, M.; Rodríguez-González, B.; Salgueiriño, V. Partial FeO-Fe $\mathrm{F}_{4} \mathrm{Phase}$ Transition Along the <111> Direction of the Cubic Crystalline Structure in Iron Oxide Nanocrystals. Part. Part. Syst. Charact. 2019, 36, 1900283. https://doi.org/10.1002/ppsc.201900283.

(50) Oh, M. H.; Cho, M. G.; Chung, D. Y.; Park, I.; Kwon, Y. P.; Ophus, C.; Kim, D.; Kim, M. 
G.; Jeong, B.; Gu, X. W.; Jo, J.; Yoo, J. M.; Hong, J.; McMains, S.; Kang, K.; Sung, Y. E.; Alivisatos, A. P.; Hyeon, T. Design and Synthesis of Multigrain Nanocrystals via Geometric Misfit Strain. Nature 2020, 577, 359-363. https://doi.org/10.1038/s41586-019-1899-3.

(51) Barreca, D.; Gasparotto, A.; Lebedev, O. I.; MacCato, C.; Pozza, A.; Tondello, E.; Turner, S.; Van Tendeloo, G. Controlled Vapor-Phase Synthesis of Cobalt Oxide Nanomaterials with Tuned Composition and Spatial Organization. CrystEngComm 2010, 12, 2185-2197. https://doi.org/10.1039/b926368n.

(52) Zhang, Z. Surface Effects in the Energy Loss near Edge Structure of Different Cobalt Oxides. Ultramicroscopy 2007, 107, 598-603. https://doi.org/10.1016/j.ultramic.2006.11.006.

(53) Pearson, D. H.; Fultz, B.; Ahn, C. C. Measurements of 3d State Occupancy in Transition Metals Using Electron Energy Loss Spectrometry. Appl. Phys. Lett. 1988, 53, 1405-1407. https://doi.org/10.1063/1.100457.

(54) Wang, Z. L.; Yin, J. S.; Jiang, Y. D. EELS Analysis of Cation Valence States and Oxygen Vacancies in Magnetic Oxides. In Micron 2000, 31, 571-580. https://doi.org/10.1016/S09684328(99)00139-0.

(55) Cullity, B. D.; Graham, C. D. Introduction to Magnetic Materials; John Wiley and Sons, 2008.

(56) Sharifi Dehsari, H.; Asadi, K. Impact of Stoichiometry and Size on the Magnetic Properties of Cobalt Ferrite Nanoparticles. J. Phys. Chem. C 2018, 122, 29106-29121. https://doi.org/10.1021/acs.jpcc.8b09276.

(57) Navrotsky, A.; Ma, C.; Lilova, K.; Birkner, N. Nanophase Transition Metal Oxides Show Large Thermodynamically Driven Shifts in Oxidation-Reduction Equilibria. Science (80-. ). 2010, 330, 199-201. https://doi.org/10.1126/science.1195875.

(58) Ramos-Docampo, M. A.; Rivas-Murias, B.; Rodríguez-González, B.; Salgueiriño, V. 
Thermodynamically Driven Oxidation-Induced Kirkendall Effect in Octahedron-Shaped Cobalt Oxide Nanocrystals. CrystEngComm 2017, 19, 5542-5548. https://doi.org/10.1039/c7ce01285c.

(59) Lu, F. H.; Dieckmann, R. Point Defects and Cation Tracer Diffusion in $\left(\mathrm{Co}_{\mathrm{x}} \mathrm{Mn}_{1-\mathrm{x}}\right)_{3-\delta} \mathrm{O}_{4}$ Spinels. Solid State Ionics 1993, 67, 145-155. https://doi.org/10.1016/0167-2738(93)903203.

(60) Dieckmann, R.; Schmalzried, H. Defects and Cation Diffusion in Magnetite (II). Berichte der Bunsengesellschaft/Physical Chem. Chem. Phys. 1977, 81, 414-419. https://doi.org/10.1002/bbpc.19770810412.

(61) Miller, A. Distribution of Cations in Spinels. J. Appl. Phys. 1959, 30, S24-S25. https://doi.org/10.1063/1.2185913.

(62) Muhich, C. L.; Aston, V. J.; Trottier, R. M.; Weimer, A. W.; Musgrave, C. B. FirstPrinciples Analysis of Cation Diffusion in Mixed Metal Ferrite Spinels. Chem. Mater. 2016, 28, 214-226. https://doi.org/10.1021/acs.chemmater.5b03911.

(63) Peterson, N. L.; Chen, W. K.; Wolf, D. Correlation and Isotope Effects for Cation Diffusion in Magnetite. J. Phys. Chem. Solids 1980, 41, 709-719. https://doi.org/10.1016/00223697(80)90077-3.

(64) Navrotsky, A.; Kleppa, O. J. Thermodynamics of Formation of Simple Spinels. J. Inorg. Nucl. Chem. 1968, 30, 479-498. https://doi.org/10.1016/0022-1902(68)80475-0.

(65) Fontaíña-Troitiño, N. F.; Rivas-Murias, B.; Rodríguez-González, B.; Salgueiriño, V. Exchange Bias Effect in $\mathrm{CoO} @ \mathrm{Fe}_{3} \mathrm{O}_{4}$ Core-Shell Octahedron-Shaped Nanoparticles. Chem. Mater. 2014, 26, 5566-5575. https://doi.org/10.1021/cm501951u.

(66) Néel, L. Aimantation à Saturation Des Ferrites Mixtes de Nickel et de Zinc. Comptes Rendus Hebd. Des Seances L Acad. Des Sci. 1950, 230, 375.

(67) Sawatzky, G. A.; Van Der Woude, F.; Morrish, A. H. Cation Distributions in Octahedral and 
Tetrahedral Sites of the Ferrimagnetic Spinel $\mathrm{CoFe}_{2} \mathrm{O}_{4}$. J. Appl. Phys. 1968, 39, 1204-1205. https://doi.org/10.1063/1.1656224. 
TOC

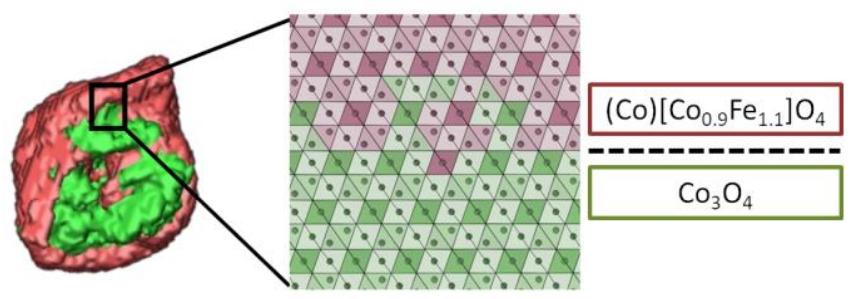

